\title{
Predicting formation lithology from log data by using a neural network
}

\author{
Wang Kexiong ${ }^{*}$ and Zhang Laibin ${ }^{2}$ \\ ${ }^{1}$ School of Petroleum Engineering, China University of Petroleum, Beijing 102249, China \\ ${ }^{2}$ School of Mechanical and Electronic Engineering, China University of Petroleum, Beijing 102249, China
}

\begin{abstract}
In order to increase drilling speed in deep complicated formations in Kela-2 gas field, Tarim Basin, Xinjiang, west China, it is important to predict the formation lithology for drilling bit optimization. Based on the conventional back propagation (BP) model, an improved BP model was proposed, with main modifications of back propagation of error, self-adapting algorithm, and activation function, also a prediction program was developed. The improved BP model was successfully applied to predicting the lithology of formations to be drilled in the Kela-2 gas field.
\end{abstract}

Key words: Kela-2 gas field, neural network, improved back-propagation (BP) model, log data, lithology prediction

\section{Introduction}

The trends of petroleum exploration and development in China are to stabilize the output from the old oilfields in east China and to develop the new oilfields in west China. New challenges, such as drilling into deeper complicated formations occur. For example, Kela-2 gas field in the Tarim Basin, China is characterized by great depth and complex lithology. During drilling, it is important to get enough information on the formation to be drilled in advance for optimizing drilling bit selection (Falconer et al, 1988). With increasing complexity in the formations to be drilled in the Kela-2 gas field, lithology prediction becomes crucial to drilling bit optimization.

It is known that there are close relationships between formation lithology and log data (Onyia, 1987), however it is impossible to get well-defined expressions, due to high nonlinearity and complication in their relationships. The conventional methods provide inaccurate means to make lithology prediction under these conditions (Gstalder and Raynal, 1966; Mason, 1987; Onyia, 1988; Raynal et al, 1971).

Neural network can establish complicated non-linear mapping between inputs and outputs. Using a neural network, we can compound the simple non-linear function by $N$ times to get the conversion between complicated functions. A back-propagation (BP) network, one of the most common neural network structures, with strong learning ability, fault tolerance and anti-jamming ability, can be used to analyze the relationships between lithology and log data. In this paper, improvement was made to the BP network model first, with the procedures presented, then a prediction program written

*Corresponding author. mail: wkx4328@sina.com Received March 5, 2008 in Visual Basic 6.0 was developed, including four main steps. The application to Well KL201 was successful.

\section{Theoretical model for lithology prediction}

\subsection{BP network model}

As shown in Fig. 1, a BP network is made up of three layers: the input layer, the output layer, and the middle "hidden" layer (Benaouda et al, 1999; Rogers et al, 1992). In the conventional BP network, the numbers of input nodes and output nodes are determined by the numbers of the input and output parameters, respectively (He, 1992; Jiao, 1992). Generally, there can be any number of hidden layers. With a multi-hidden-layer network, a small number of weight adjustments is needed for the network to learn the knowledge of the training samples and store them in the form of the weight distribution. However, theoretical studies indicate that if one single hidden layer has enough nodes, the identification precision needed also can be reached, so one-hidden-layer network is used for simplicity (Zhuang et al, 1992)

In the BP network, the commonly used activation function is the Sigmoid function and can be written as follows (Wiener et al, 1991):

$$
f(x)=\frac{1}{1+\exp (-x)}
$$

Normalization is usually used in the BP model because the input and output parameters may not fall in the range of zero and unity.

\subsection{Improved BP model}

In the BP algorithm, slow convergence always exists, so several improvements are made to get better computation 


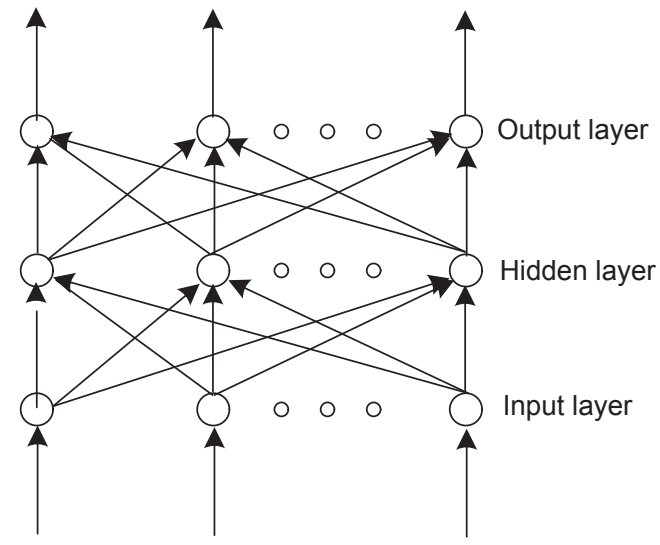

Fig. 1 BP neural network

performance (Bueno et al, 2006).

\section{1) Back propagation of total sample error}

In order to train a neural netork to perform some task, we must adjust the weights of each unit in such a way that the error between the desired output and the actual output is reduced. This process requires that the neural network computer the error derivative of the weights. In other words, it must calculate how the error changes as each weight is increased or decreased slightly. The back propagation algorithm is the most widly used method for determining the error derivative of the weights. Because the neural network is trained with different samples, the back propagtion of error, which is the average error of all training samples, accelerates the convergence over the back propagation of each singlesample-error and provides a stable learning process.

\section{2) $\eta$ self-adapting algorithm}

Learning rate $\eta$ takes a relatively large value when $w_{j i}$ is far from the stable point, and a relatively small value when $w_{j i}$ is close to the stable point. Using this method, the convergence increases greatly.

$$
\eta(t+1)=\frac{\eta(t) E(t)}{E(t-1)}
$$

with

$$
E=\left(\sum E_{\mathrm{p}}\right) / N
$$

where $N$ is the number of training samples.

\section{3) Selection of $\alpha$ value}

Constant $\alpha$, a momentum factor, plays an opposite role to $\eta$, and self-excites when it is larger than 1 . So we can use the self-exciting function of $\alpha$ to approach a optimal point quickly. When the value of error function decreases, the value of $\alpha$ should be larger than 1. When the value of error function is stable or increases, the value of $\alpha$ should be less than 1 .

\section{4) Selection of special functions}

$P-1$ hidden units can remember the values of $K$ samples, when using some special functions, such as unit step and
Sigmoid functions, as hidden-layer activation function for the 3-layer neural network. So for the 3-layer nerual network, the number of hidden units cannot be less than $P-1$, with an empirical value of $2 P+1$.

The flow chart of the improved BP algorithm is as follows:

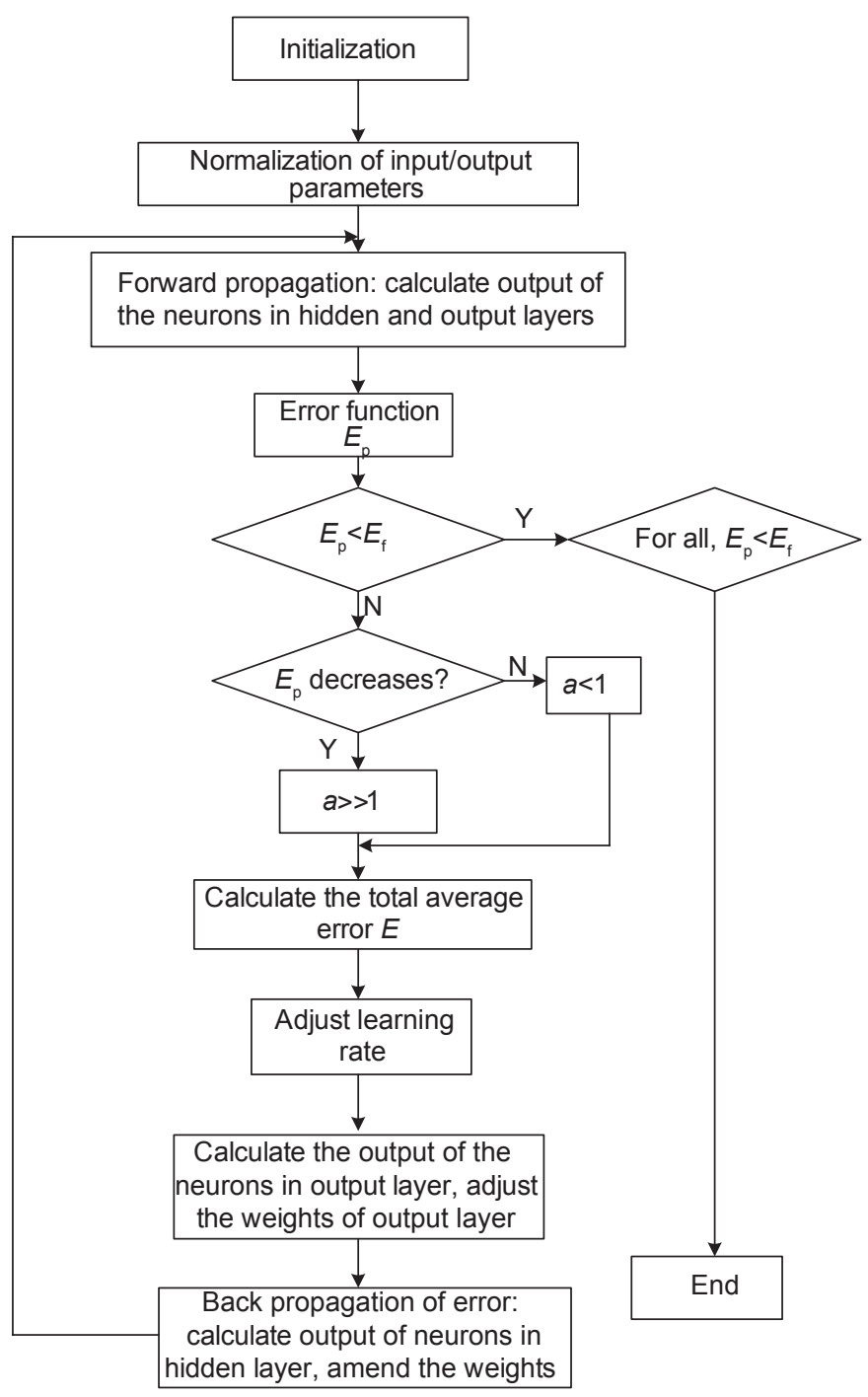

Fig. 2 BP flow chart

\section{Computer prograrm for predicting formation lithology}

\subsection{Selection of training samples}

The purpose of neural network learning or training is to iteratively update the network weights to minimize the learning error, and then the trained neural network can make predictions for new cases. So the reliability of the prediction model is related to the training samples. For a region, training samples do not necessarily come from one key well, other wells in this region should also be included. For this consideration, the training samples are from the representative 
wells in the Kela-2 gas field, and mainly from sandstone and mudstone, which dominate the penetrated formations in the Kela-2 gas field.

\subsection{Selection of useful log data}

In general, estimates of formation lithology can be obtained by using conventional techniques, such as sonic $\log$, gamma ray log, etc, so the training sample data are from sonic and gamma ray logs in sandstone and mudstone in Keyi structural belt, as shown in Table 1 .

\subsection{Identification mode}

There are two modes for formation identification: pointto-point and layer-to-layer, in which the former is adopted in this paper.

\subsection{Parameters of BP network}

In this paper, a three-layer BP neural network was used according to the data of training samples. The input neurons were interval transit time (sonic log) and gamma log, and the hidden layer consisted of 5 neurons, with output layer only one neuron of lithology. The standard input of sonic log was $200 \mu \mathrm{s} / \mathrm{ft}$, the gamma log, $150 \mathrm{API}$, and the lithology, 1. The learning rate was set as 0.8 , and the standard error, 0.005 . Table 2 shows the weight values, which come from training sample data in Table 1.

\subsection{Prediction program based on improved BP model}

According to the improved BP algorithm and flow chart above-mentioned, a program for predicting lithology was

Table 1 Training sample data

\begin{tabular}{|c|c|c|c|c|c|c|c|c|}
\hline \multirow{2}{*}{ No. } & \multirow{2}{*}{ Well name } & \multirow{2}{*}{$\begin{array}{l}\text { Well depth } \\
\text { m }\end{array}$} & \multirow{2}{*}{ Stratum } & \multirow{2}{*}{ Lithology } & \multicolumn{2}{|c|}{ Input } & \multicolumn{2}{|c|}{ Expected output } \\
\hline & & & & & $\begin{array}{l}\text { Interval transit } \\
\text { time, } \mu \mathrm{s} / \mathrm{ft}\end{array}$ & Gamma, API & Lithology & Value \\
\hline 1 & Kela-33 & 3424 & E & Red mudstone & 103 & 109 & Mudstone & 1 \\
\hline 2 & Kela-3 & 3575 & K & Red gritstone & 84.5 & 53.1 & Sandstone & 0 \\
\hline 3 & Kela-202 & 4380 & $\mathrm{~J}$ & Red aleurolite & 98.9 & 39.2 & Sandstone & 0 \\
\hline 4 & Kela-202 & 5878 & K1S & Red aleurolite & 70.2 & 45.3 & Sandstone & 0 \\
\hline 5 & Kela-202 & 5880 & K2S & Red aleurolite & 65.4 & 45.6 & Sandstone & 0 \\
\hline 6 & Kela-202 & 5882 & K3S & Quartz glutinite & 64.8 & 37.4 & Sandstone & 0 \\
\hline 7 & Kela-3 & 3930 & K & Red and brown packsand & 63.2 & 61.6 & Sandstone & 0 \\
\hline 8 & Kela-3 & 4402 & $\mathrm{~J} 2 \mathrm{Q}$ & Black mudstone & 75.8 & 144 & Mudstone & 1 \\
\hline 9 & Kela-3 & 4540 & $\mathrm{~J} 2 \mathrm{~K}$ & Grey packsand & 63.5 & 128 & Sandstone & 0 \\
\hline 10 & Kela-3 & 4545 & $\mathrm{~J} 3 \mathrm{~K}$ & Grey gritstone & 70 & 86 & Sandstone & 0 \\
\hline 11 & Kela-3 & 990 & J1A & White glutinite & 63.75 & 60.8 & Sandstone & 0 \\
\hline 12 & Kela-3 & 4592 & $\mathrm{~J} 1 \mathrm{Y}$ & Deep grey mudstone & 73.7 & 97 & Mudstone & 1 \\
\hline
\end{tabular}

Table 2 Weight values and threshold values of sample data

\begin{tabular}{c|cccc}
\hline \multirow{3}{*}{ Weight } & -8.731137 & -5.60282 & -40.02768 & -1.56837 \\
& -17.2273 & -4.04653 & $-2.01 \mathrm{E}-02$ & -12.7473 \\
& -10.62275 & -4.35111 & -14.93431 & -42.0913 \\
& -20.02995 & -16.6711 & -14.00656 & \\
\hline \multirow{2}{*}{ Threshold } & 6.306106 & 13.75476 & 8.104316 & \\
& 5.333366 & 5.887748 & 28.9638 & \\
\hline
\end{tabular}


developed with Visual Basic 6.0. This program mainly included the sample training module, parameter prediction module, and data editing files, which can be used to predict formation lithology through processing the log data.

\section{Application}

From the log data of Well Kela-201 in Keyi structural belt, 10 sets of data were extracted. The BP neural network program was used to predict the formation lithology, with the output results and relative errors listed in Table 3.
In Table 3, the expected value of 1 represents mudstone, the 0 , sandstone. If the output value is near or equal to 1 , the lithology of this point is mudstone; and if the output value is near or equal to 0 , it is sandstone. Because the formation lithology is very complex, one seldom encounters pure sandstone or mudstone, and the formation lithology is mostly sandy mudstone or muddy sandstone. As to other output value of the network we may consider the lithology of this point as muddy sandstone or sandy mudstone qualitatively.

\section{Conclusions}

Table 3 Predicted results and relative errors

\begin{tabular}{|c|c|c|c|c|c|}
\hline \multirow{2}{*}{ No. } & \multicolumn{2}{|c|}{ Input } & \multicolumn{3}{|c|}{ Output } \\
\hline & Interval transit time, $\mu \mathrm{s} / \mathrm{ft}$ & Gamma, API & Expected value & Exact value & Accordance \\
\hline 1 & 97.7 & 95.8 & 1 & 0.9997 & Yes \\
\hline 2 & 102.6 & 82.8 & 1 & 0.9933 & Yes \\
\hline 3 & 109.3 & 107.4 & 1 & 1.0000 & Yes \\
\hline 4 & 101.9 & 80.3 & 1 & 0.9857 & Yes \\
\hline 5 & 73.4 & 67.9 & 0 & 0.0948 & Yes \\
\hline 6 & 61.2 & 69.5 & 0 & 0.1022 & Yes \\
\hline 7 & 64.8 & 52.7 & 0 & 0.0018 & Yes \\
\hline 8 & 66.3 & 55.4 & 0 & 0.0042 & Yes \\
\hline 9 & 64.1 & 61.5 & 0 & 0.0258 & Yes \\
\hline 10 & 68.8 & 64.4 & 0 & 0.0781 & Yes \\
\hline
\end{tabular}

1) Prediction of formation lithology from sonic and gamma ray log data by using a BP neural network is applicable, compared with conventional methods.

2) For sandstone and mudstone, the improved BP model shows acceptable stability, with the results agreeing well with measured values.

3) Expected values in output data mean lithology, 1 being sandstone and 0 being mudstone, and the intermediate values should be sandy mudstone or muddy sandstone.

4) The prediction results depend on sample data, so when prediction is made in other regions, the model should be retrained.

\section{References}

Benaouda D, Wadge G, Whitmarsh R B, et al. Inferring the lithology of borehole rocks by applying neural network classifiers to downhole logs: An example from the Ocean Drilling Program. Geophysical Journal International. 1999. 136(2): 477-491
Bueno E O J, Pérez I C, Escamilla G, et al. Applications of artificial neural networks and dipole sonic anisotropy in low-porosity, naturally fractured, complex lithology formations in the Southern Land Region of Mexico. First International Oil Conference and Exhibition in Mexico held in Cancun, Mexico, 31 August-2 September 2006 (SPE paper 103662)

Falconer I G, Burgess T M and Sheppard M C. Separating bit and lithology effects from drilling mechanics data. SPE/IADC Drilling Conference held in Dallas, Texas, 28 February-2 March 1988 (SPE paper 17191)

Gstalder S and Raynal J. Measurement of some mechanical properties of rocks and their relationship to rock drillability. Journal of Petroleum Technology. 1966. 18(8): 991-996

He M Y. Neural Computing. Xi'an: Xidian University Press. 1992. 156-178 (in Chinese)

Jiao L C. The Theory of Artificial Neural Networks. Xi'an: Xidian University Press. 1992. 35-51 (in Chinese)

Mason K L. Tricone bit selection using sonic logs. SPE Drilling Engineering. 1987. 2(2): 135-142 (SPE paper 13256) 
Onyia E C. Geology drilling log: A computer database system for drilling simulation. SPE Drilling Engineering. 1987. 2(1): 27-36

Onyia E C. Relationship between formation strength, drilling strength and electric log properties. SPE Annual Technical Conference and Exhibition held in Houston, Texas, 2-5 October 1988 (SPE paper 18166)

Raynal J C, Serge A, Sagot A M, et al. Organization of field tests and evaluation of tricone bit performance using statistical analysis and sonic logs. Journal of Petroleum Technology. 1971. 23(4): 506-512

Rogers S J, Fang J H, Karr C L, and Stanley D A. Determination of lithology from well logs using a neural network. AAPG Bulletin. 1992. 76(5): 731-739

Wiener J M, Rogers J R, and Moll R F. Predicting carbonate permeabilities from wireline logs using a back-propagation neural network. 61st Annu. SEG Int. Mtg. Abstract. 1991

Zhuang Z Q, Wang X F, Wang D S, et al. Neural Networks and Neural Computers. Beijing: Science Press. 1992 (in Chinese)

(Edited by Sun Yanhua) 